$12-4-2005$

\title{
Accounting for US Regional Real Exchange Rates
}

\author{
Lein Lein Chen \\ University of Nevada - Las Vegas \\ Seungmook Choi \\ University of Nevada \\ John Devereux \\ Queens College, CUNY
}

Follow this and additional works at: https://fordham.bepress.com/crif_seminar_series

Part of the Finance and Financial Management Commons

\section{Recommended Citation}

Chen, Lein Lein; Choi, Seungmook; and Devereux, John, "Accounting for US Regional Real Exchange Rates" (2005). CRIF Seminar series. 8.

https://fordham.bepress.com/crif_seminar_series/8 


\title{
Accounting for US Regional Real Exchange Rates
}

\author{
Lein Lein Chen \\ Department of Economics, University of Nevada, Las Vegas \\ Las Vegas, Nevada, 89154-6005 \\ Seungmook Choi \\ Department of Finance, University of Nevada, Las Vegas \\ Las Vegas, Nevada, 89154-6008 \\ John Devereux \\ Department of Economics, Queens College, CUNY, Flushing \\ New York, New York, 11367-1597
}

\begin{abstract}
Summary
We examine the relationship between the relative price of nontradables and real exchange rate movements for fixed exchange rate regimes. We have two findings. First we show that purchasing power parity holds strongly for tradables across US regions. As a result, nontradables play a central role in regional real exchange rate movements. Using BLS regional data, we find that changes in the relative price of nontradables explain up to eighty percent of regional real exchange changes over medium and long run horizons. Second, we show that nontradables can account for a large portion of real exchange rates changes internationally with high expenditure shares.
\end{abstract}

December 4, 2005

Third Draft 


\section{Introduction}

The distinction between tradables and nontradables is at the core of open economy macroeconomics. ${ }^{1}$ Engel (1999), however, has recently questioned the empirical relevance of this distinction. Using various real exchange rate measures, he finds that changes in the relative price of nontradeables explain very little of U.S. real exchange rate movements at short or medium time horizons for fixed or floating exchange rate regimes. As noted by Obstfeld and Rogoff (2000) and Obstfeld (2001), these findings are devastating for traditional tradables/nontradables models.

Engel's (1999) results are plausible for floating exchange rates where changes in nominal exchange rates tend to overwhelm price level movements. We would, however, expect changes in the relative price of nontraded goods to play a larger role where exchange rates are fixed. Mendoza (2000) provides some early support for this position. Using data for the Mexican/US real exchange rate, he finds that changes in the prices of nontradables explain seventy percent of real exchange rate movements during periods of fixed rates or managed floating.

In this paper, we examine the relationship between the relative price of nontraded goods and the real exchange rate with data from four US regions, the Northeast, Midwest, South and West. In terms of size and economic structure, US regions are comparable to large developed countries. They allow us therefore to study real exchange rate movements in economies with permanently fixed rates as well as high levels of factor mobility and goods market integration. Furthermore the US regional data are superior to that used internationally in that they are collected for identical sets of goods and services,

\footnotetext{
1 The modern interest in the tradables/nontradables model begins with Salter (1959). Obstfeld and Rogoff (1996) survey work in this tradition.
} 
the weights are similar across regions for broad aggregates and the same methods are used to introduce new goods and to adjust for quality changes. Thus, many of the data difficulties faced internationally are not present for US regions. ${ }^{2}$

We show that changes in the relative price of nontradables account for a large portion of regional real exchange rate movements over medium and longer run horizons. Indeed, they explain eighty percent of real exchange rate changes at horizons above two years. The dominance of nontradables is explained by the fact that departures from purchasing power parity (PPP) for tradables are short lived at the regional level.

The final portion of the paper compares the US regional and international evidence on the relative importance of nontradables. We argue that differences between the regional and the international results arise because traded goods markets are better integrated across US regions. In addition, we show that the findings for international data depend on the share of nontradables in expenditure. Using plausible expenditure shares, we find that nontradables can account for fifty percent of US real exchange rate changes with Germany, France and Japan for the Bretton Woods system.

We proceed as follows. Section two outlines real exchange rate accounting. Section three applies real exchange rate accounting to regional data while section four extends the results to city data. Section five discusses the relative importance of nontradables for Canada, France, Germany, Italy and Japan during fixed rates between 1962 and 1972. Section six summarizes.

\footnotetext{
2 Of course, the existence of a common language, legal system and zero trade barriers within the US complicates any attempt to compare regional real exchange rate behavior to fixed regimes internationally.
} 


\section{Real Exchange Rate Accounting}

This section introduces real exchange rate accounting drawing on Engel (1999). The next section applies the approach to regional data.

We assume that the overall price level for the $i$ th region is given by (1) where $p_{i}$ is the log of price level and $\mathrm{p}_{i}^{\mathrm{T}}$ and $\mathrm{p}_{\mathrm{i}}^{\mathrm{N}}$ are traded and nontraded prices respectively in $\operatorname{logs}$ and $\alpha$ is the share of the nontradables in expenditure.

$$
p_{i}=(1-\alpha) p_{i}^{T}+\alpha p_{i}^{N}
$$

We further assume that the share of nontradables is the same for all regions. Following Engel (1999), we express the real exchange rate between the $i^{\prime} t h$ and $j^{\prime} t h$ regions, denoted by $\mathrm{q}_{\mathrm{ij}}$, as:

$$
\begin{aligned}
& \mathrm{q}_{\mathrm{ij}}=\mathrm{x}_{\mathrm{ij}}+\mathrm{y}_{\mathrm{ij}} \\
& \text { where } \\
& \mathrm{q}_{\mathrm{ij}}=\mathrm{p}_{\mathrm{i}}-\mathrm{p}_{\mathrm{j}} \\
& \mathrm{x}_{\mathrm{ij}}=\mathrm{p}_{\mathrm{i}}^{\mathrm{T}}-\mathrm{p}_{\mathrm{j}}^{\mathrm{T}} \\
& \mathrm{y}_{\mathrm{ij}}=\alpha\left(\left(\mathrm{p}_{\mathrm{i}}^{\mathrm{N}}-\mathrm{p}_{\mathrm{i}}^{\mathrm{T}}\right)-\left(\mathrm{p}_{\mathrm{j}}^{\mathrm{N}}-\mathrm{p}_{\mathrm{j}}^{\mathrm{T}}\right)\right)
\end{aligned}
$$

Equation (2) states the real exchange rate is equal to the relative traded price level, given by $\mathrm{x}$, and the expenditure weighted relative price of nontradables across regions, given by y. As Engel (1999) points out, the traditional approach focused on the 
internal relative price of nontradables. Equation (2), in contrast, shifts our attention to the relative price of nontradables across regions/countries.

Equation (2) shows that the degree of goods market integration for tradables and the expenditure share of nontradables determine the relative importance of nontradables for real exchange rate movements. The smaller the deviations from purchasing power parity (PPP) for tradables, the greater are the role of nontradables. In the limit, where PPP holds perfectly, all real exchange rate changes are due to nontradables prices.

Furthermore, the higher is $\alpha$, the share of nontradables in expenditure, the greater is the contribution of nontradables to real exchange rate movements.

Engel (1999) measures the relative importance of tradables by calculating the portion of the mean squared error, MSE, of changes in the real exchange rate, $\mathrm{q}$, attributable to changes in the relative price of tradables, x. He provides two decompositions. The first assumes that there is a zero correlation between $\mathrm{x}$ and $\mathrm{y}$. $\mathrm{He}$ terms this measure B1.

$$
B 1=\frac{\operatorname{MSE}\left(x_{t}-x_{t-n}\right)}{\operatorname{MSE}\left(x_{t}-x_{t-n}\right)+\operatorname{MSE}\left(y_{t}-y_{t-n}\right)}
$$

The second measure, B2, applies when there is comovement between the $\mathrm{x}$ and $\mathrm{y}$ variables. It attributes half of the comovement to each. ${ }^{3}$

$$
B 2=\frac{\operatorname{MSE}\left(x_{t}-x_{t-n}\right)+\operatorname{Mean}\left(x_{t}-x_{t-n}\right) \operatorname{Mean}\left(y_{t}-y_{t-n}\right)+\operatorname{Cov}\left(x_{t}-x_{t-n}, y_{t}-y_{t-n}\right)}{\operatorname{MSE}\left(q_{t}-q_{t-n}\right)}
$$

\footnotetext{
${ }^{3}$ When the correlation between $\mathrm{x}$ and $\mathrm{y}$ is positive, B1 will understate the relative importance of tradables. With a negative correlation, it will overstate the importance of tradables. Mendoza (2000) provides further discussion.
} 
We now apply these measures to regional and city data.

\section{Regional Real Exchange Rates}

The BLS provides bi-monthly price indices for the Northeast, the Midwest, the South and the West. Following Engel (1999), we measure traded goods as the commodity portion of the consumer price index. Nontradables correspond to services including housing. The BLS regional price indices for services/commodities are available from 1978. ${ }^{4}$ While these measures may not be perfect, there seem to be no alternatives at the regional level.

To calculate $y$, that is the expenditure weighted relative price of nontradables, we set the nontradables expenditure share equal to 0.51 . We obtain this estimate from a regression procedure used by Engel (1999). It is best seen as the average share for the period. ${ }^{5}$

Figure 1 plots bi-monthly regional real exchange rates from February 1978 to December 2001 measured in logs along with the $\mathrm{x}$ and $\mathrm{y}$ variables as defined earlier. We use a Northeast base but the general patterns hold for all regional bases.

\footnotetext{
${ }^{4}$ We use the Consumer Price Index for all urban consumers (new series) at http://www.bls.gov/cpi/home.htm\#data. The BLS weights have changed over time whereas we use constant geometric weights. For this reason, there are slight differences between our price levels and those of the BLS.

5 The share of services in consumer expenditures is increasing over time. The CPI weights for December 2000 show that services including housing are now close to sixty percent of US consumer spending. These weights are at ftp://ftp.bls.gov/pub/special.requests/cpi/usri2000.txt.
} 
Figure 1

\section{Regional Real Exchange Rates}

(a) The West/Northeast Rate

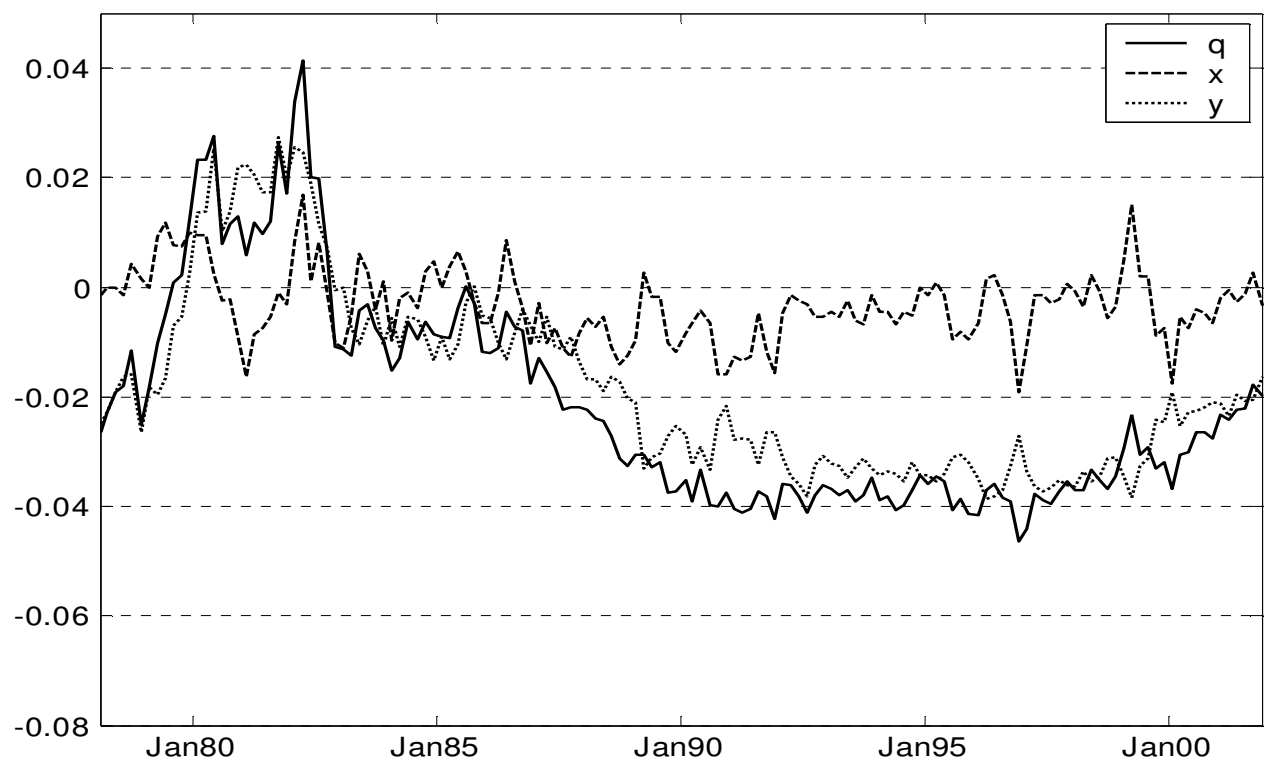

(b) The Midwest/Northeast Rate

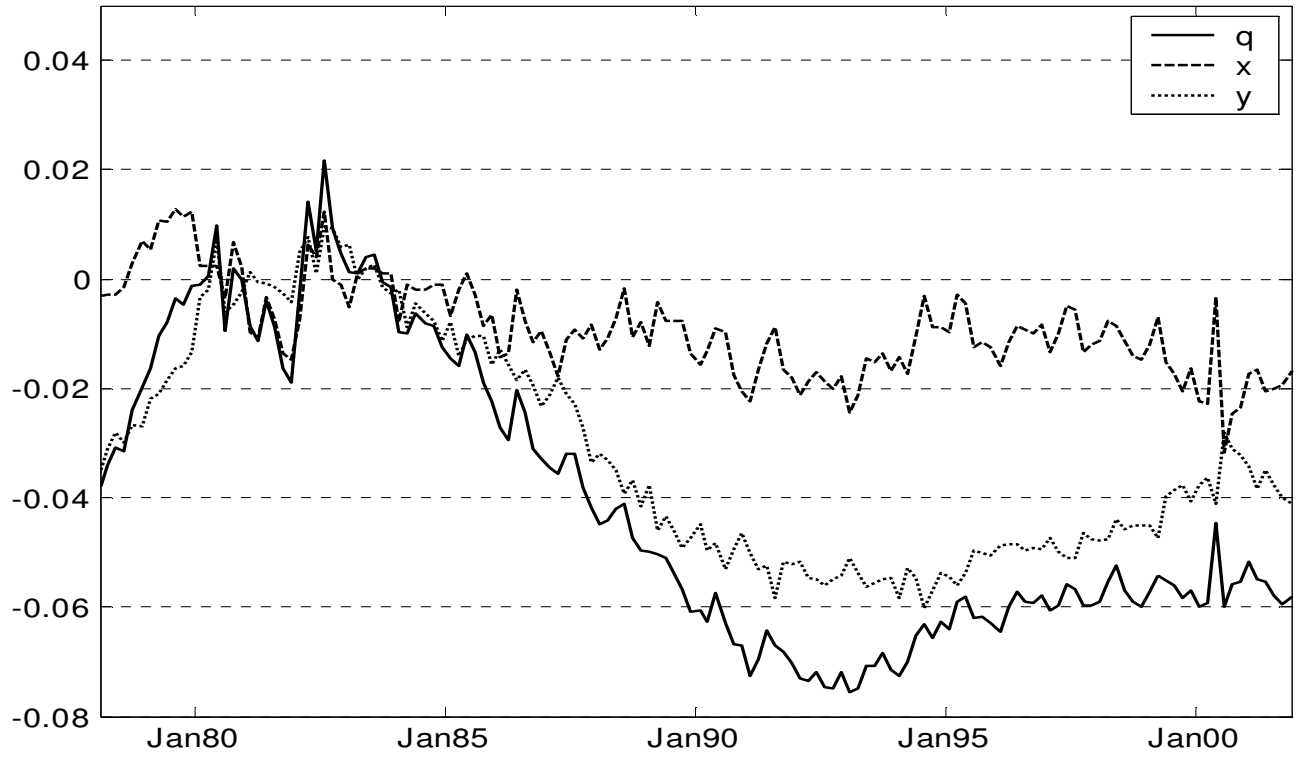


(c) The South/Northeast Rate

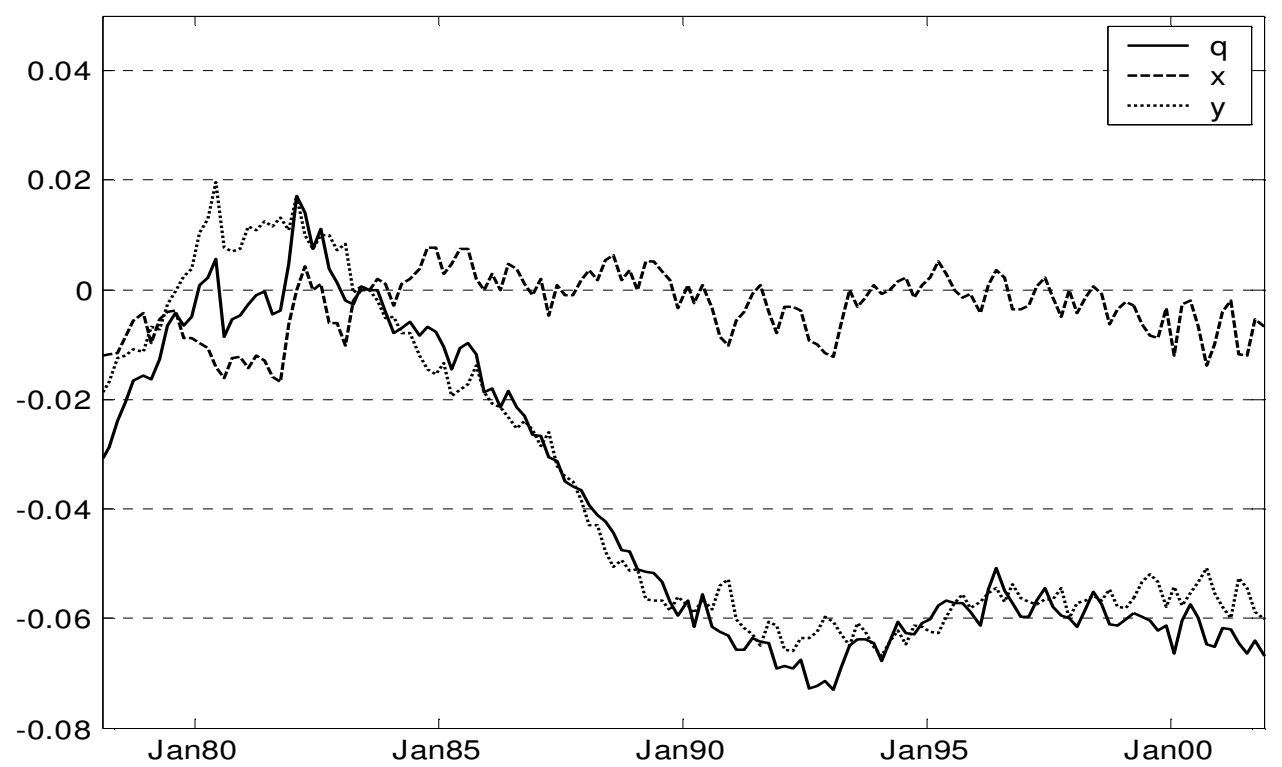

The regional data show three features. First, changes in the relative price of

traded goods are small and transitory. Applying standard stationarity tests, we find that the half-life of deviations of tradables from PPP varies from three months to eight months depending on the region. ${ }^{6}$ This means that the adjustment of tradable prices to PPP for US regions is exceptionally fast. The small deviations from PPP and the faster speeds of adjustment reflect high US levels of goods market integration. ${ }^{7}$

Second, there is a close relationship between the $\mathrm{q}$ and the y variables in the regional data. In other words, real exchange rate movements are closely correlated with the expenditure weighted relative price of nontradables.

\footnotetext{
${ }^{6}$ We calculate the half-life as $-\ln (2) / \ln \rho$ where $\rho$ is the AR 1 coefficient. This yields half-lives for tradables of $0.26,0.81,0.75$ years for the West, Midwest and South. We adopt this measure to facilitate comparison with the previous literature. Note, however, that it has problems. In particular it is biased downwards in small samples see Murray and Papell (2002).

${ }^{7}$ Helliwell (1998) and Obstfeld and Rogoff (2000) summarize the evidence that markets are better integrated within than across economies.
} 
Finally, changes in the real exchange rate and the relative price of nontradables are persistent. 8

Figure 2 gives the results of the MSE decompositions. The vertical axis gives the proportion of real exchange rate changes attributable to tradables while the horizontal axis gives the time horizon measured bi-monthly. We provide both the B1 and the B2 decompositions. ${ }^{9}$

Figure 2

\section{The Relative Importance of Tradables for US Regional Real Exchange Rates}

a. The West/Northeast Rate

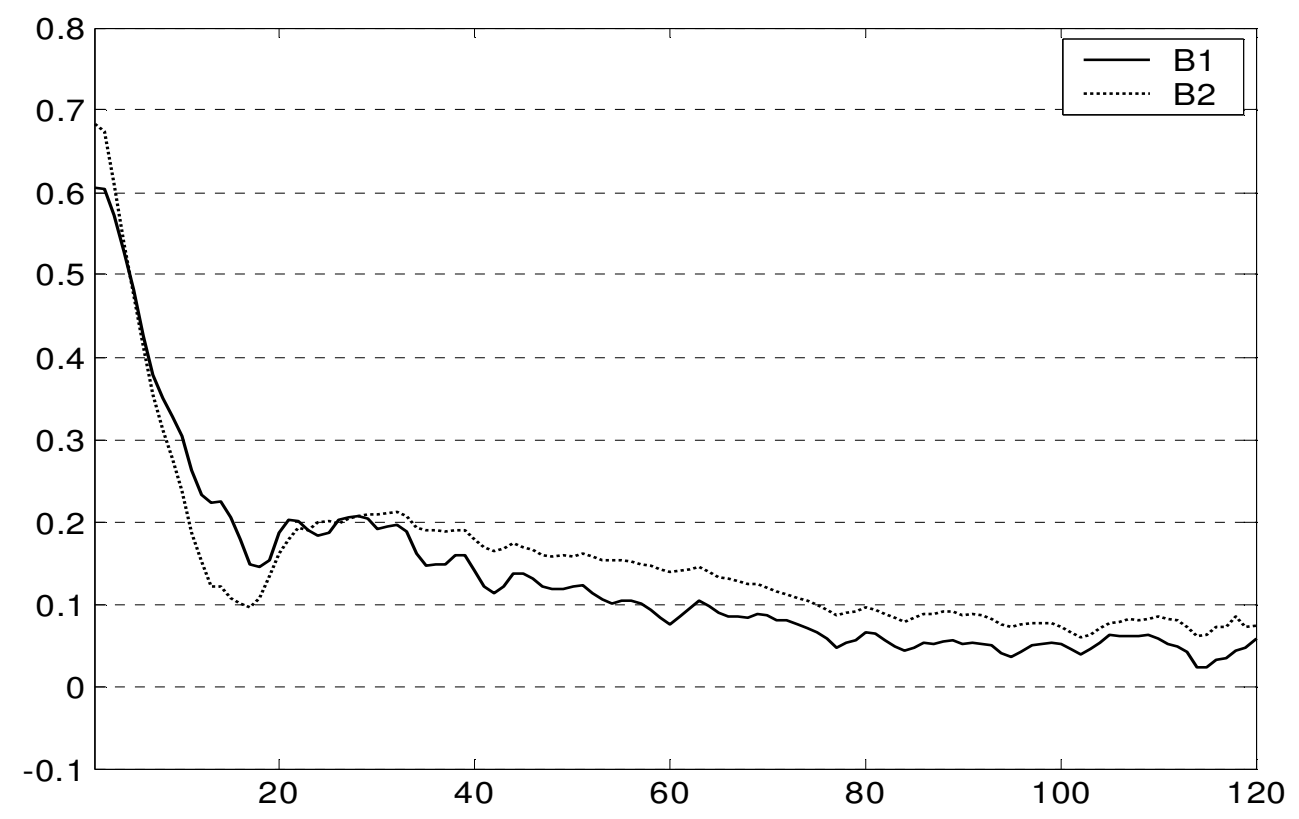

\footnotetext{
8 The half-lives are 2.48, 4.4 and 5.8 years respectively for the West, Midwest and South.

9 The correlations are negative at horizons less than forty months while they become positive at longer horizons. Mendoza (2000) finds a negative correlation between these variables for the US/Mexican real exchange rate in periods of managed floating and fixed exchange rates.
} 
b. The Midwest/Northeast Rate

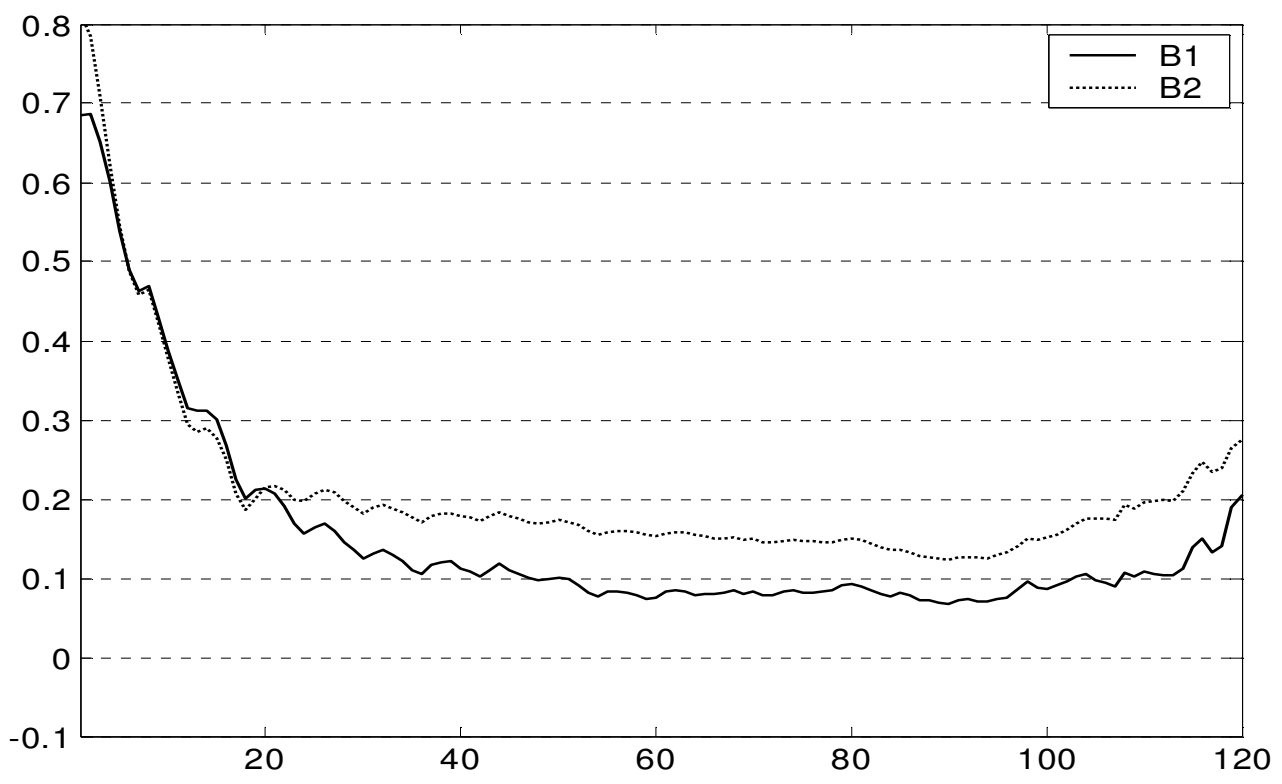

c. The South/Northeast Rate

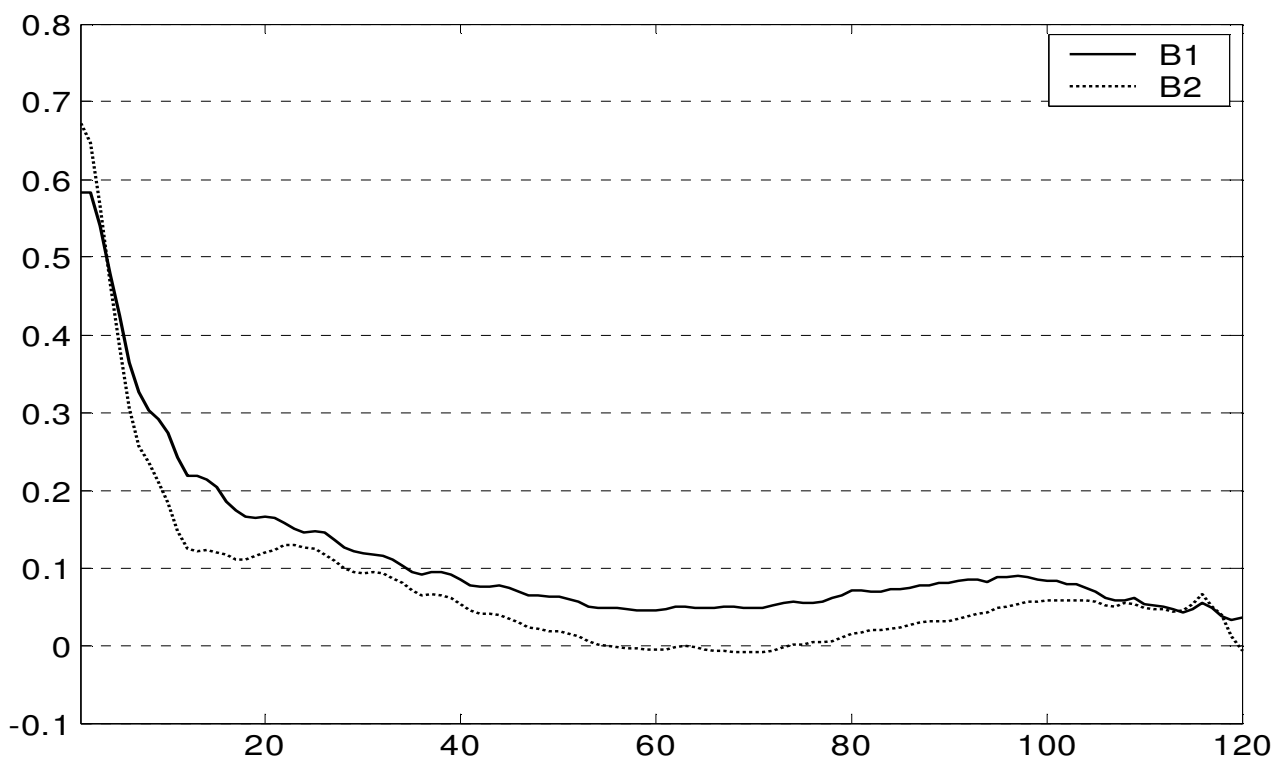


We use time horizons from two to two hundred and forty months. Keep in mind, however, that the longer the horizon the less reliable the results since they are based on fewer observations.

The MSE decompositions show that tradable prices are the major source of regional real exchange rate movements at short time horizons. At two months, they account for eighty percent of real exchange rate changes. Over the medium and longer run, however, real exchange rate changes are due almost entirely to changes in the relative price of nontradables. By one year, the contribution of tradables is below fifty percent. By two years, it is down to twenty-five percent. After five years, tradables account for less than twenty percent of real exchange rate changes.

These results are robust. They do not depend on our Northeast base. Only for the Midwest/West real rate do tradables account for more than forty percent of real exchange rate changes at horizons greater than five years. Second, our findings hold for both the B1 and B2 measures. Finally, the results are not sensitive to our assumed expenditure shares.

What are the implications of regional results for fixed exchange rate regimes such as the Euro? ${ }^{10}$ As we have seen, the relative importance of nontradables depends on the strength of market integration for traded goods. If US experience is a guide, then deviations from PPP for tradables will be smaller and shorter lived over time for the Euro area as market integration improves. ${ }^{11}$

\footnotetext{
${ }^{10}$ Cecchetti, Mark and Sonora (2002) use US city price data to provide an upper bound on speeds of adjustment for fixed rates. It is an upper bound because factor mobility and market integration is higher within the US.

11 Rogers (2002) argues that goods market integration has improved over time for the Euro.
} 


\section{City Real Exchange Rates}

The BLS also provides data for cities. To date, the intranational literature has focused on these data. ${ }^{12}$ In our view, US cities are too small and too specialized in production to tell us much about international real exchange rate movements. ${ }^{13}$ Given the focus in the intranational literature, it is important to verify that nontradables are also important for city real exchange rates.

The BLS city indices date from 1913. The prices indices for services/commodities, however, are available only since 1967 . These data are monthly for New York, Chicago and Los Angeles. For the other cities, they are bi-monthly with some available in odd months while others are for even months. Complicating matters, the reporting months have changed over time. Furthermore, the bi-monthly data were not collected for some years after 1986. These problems have forced us concentrate on annual data. ${ }^{14}$

\footnotetext{
12 The city literature is growing rapidly. It includes Engel and Rogers $(1996,2001)$ and Parsley and Wei (2001) who compare relative price variability within and across economies with city price data. Parsley and Wei (1996) and O'Connell and Wei (2002) study the law of one price (LOOP) with disaggregated city price data. Our work is closest to Culver and Papell (1999), Cecchetti, Mark and Sonora (2002) and Chen and Devereux (2003) who use city data to test aggregate versions of purchasing power parity (PPP). More generally, the city literature is part of a wider movement that uses intranational data to understand issues in macroeconomics and international trade and finance see Hess and Van Wincoop (2000).

13 Using market exchange rates, the Gross Metropolitan Product of the New York CMSA in 2000 was 439 billion dollars that is just twenty percent higher than the GDP of the Netherlands. The Gross Metropolitan product for SMA's such as Kansas City or Cincinnati is smaller than Denmark or Ireland. The data on Metro GDP is from the US Council of Mayors at http://www.usmayors.org/citiesdrivetheeconomy/index3.html
}

${ }^{14}$ In terms of time span, our city series are similar to those used by Engel (1999) for the combined fixed and floating periods. 
We have annual data for twenty cities from 1967 to $2001 .^{15}$ After experimenting with various bases, we found that while the specifics depend on the base, the overall patterns did not. To summarize our findings, we present the average of the results for all 190 separate city real exchange rates for horizons from one to ten years.

Figure 3 provides the results. The vertical axis gives the proportion of real exchange rate changes attributable to tradables while the horizontal axis gives the time horizon measured in years. The solid lines in the figures represent the mean of the 190 city pairs while the dotted lines are one standard deviation below and above the average.

We derive these results using an expenditure share of 0.49 for nontradables obtained from Engel's (1999) regression procedure.

\footnotetext{
15 They are: New York, Philadelphia, Boston, Pittsburgh, Chicago, Detroit, St Louis, Cleveland, Minneapolis, Milwaukee, Cincinnati, Kansas City, Atlanta, Dallas, Houston, Honolulu, Los Angeles, San Diego, San Francisco and Seattle.
} 
Figure 3

The Relative Importance of Tradables for City Real Exchange Rates
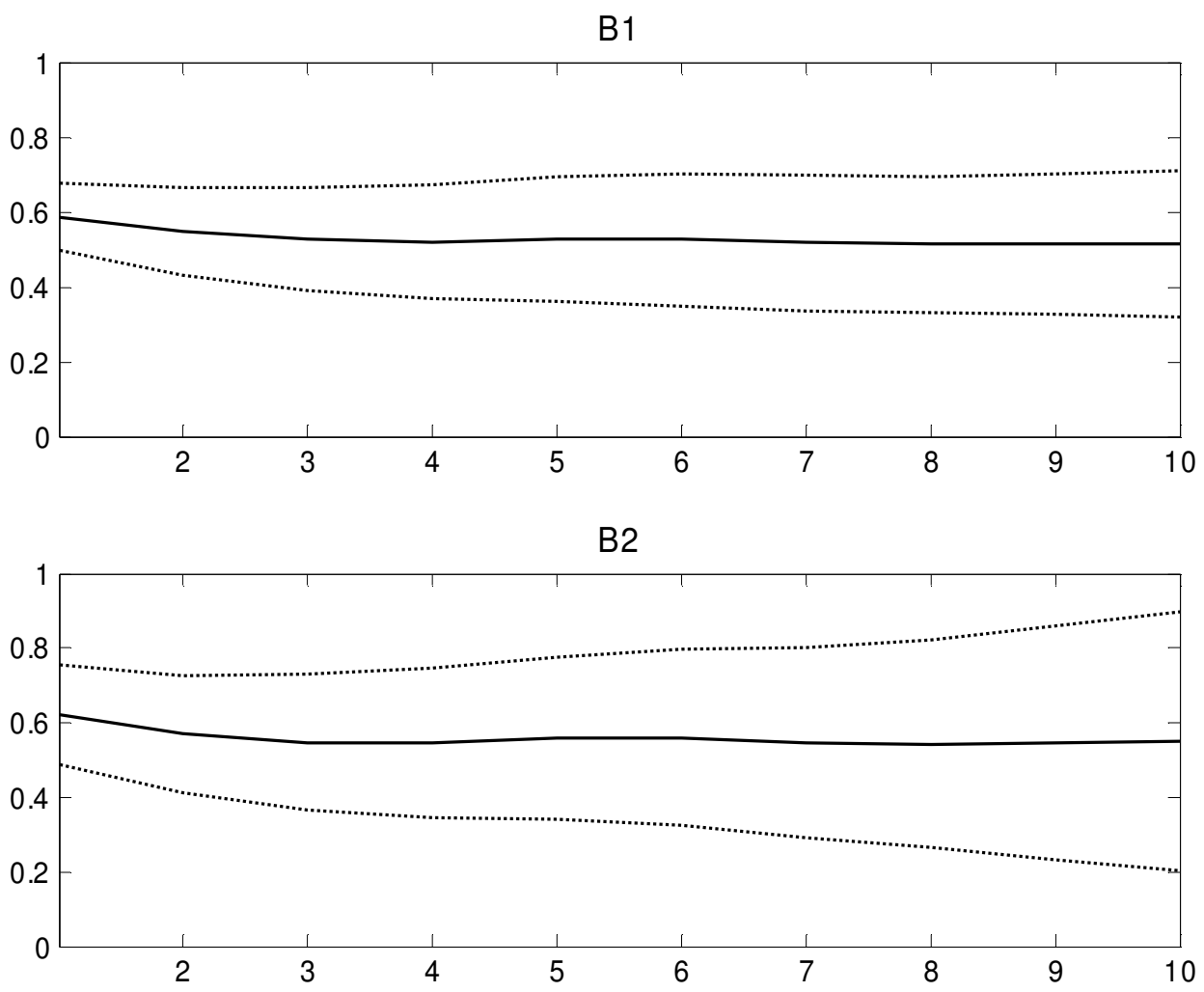

On average, both tradables and nontradables account for city real exchange rate movements at all time horizons. The city results differ from the regional case where only nontradables matter for medium and long run horizons. The relative importance of tradables is also higher for city real exchange rates as the average is over fifty percent.

The differences between the regional and city results are mainly from tradables where the divergences of tradables from purchasing power parity are larger and more persistent than at the regional level. As we discussed earlier, speeds of adjustment for tradables are less than one year in the regional data. Our calculations suggest, however, 
that speeds of adjustment for tradables for the city data are much slower, with most in the three to five year ranges. ${ }^{16}$

What explains the differences between the city and regional results? As previously argued, cities are more specialized in production than regions and hence are subject to larger shocks. There is also evidence that some city real exchange rates exhibit trends. To give one instance, the San Francisco price level has appreciated relative to other cities since the early part of the last century.

\section{The International Evidence}

Using monthly data from Canada, France, Germany, Italy and Japan and the US, Engel (1999) finds that nontradables account for a tiny portion of real exchange rate movements using a US base between January1962 and December 1969.

What explains the differences between the regional and international results? Recall from (2) that the relative importance of nontradables depends on how well PPP holds and the expenditure shares for nontradables. As we have seen, deviations from purchasing power parity for tradables are small and speeds of adjustment are fast for US regions. This is certainly not the case internationally.

The other reason why nontradables matter for regional rates is high expenditure shares. We use an expenditure share of 0.51. Engel's (1999) shares are lower. Canada is 0.4, France 0.25, Germany 0.28, Italy 0.24 , Japan 0.31 and the United States $0.46 .{ }^{17}$

\footnotetext{
16 The average for all separate city real rates is 4.3 years. Cecchetti, Mark and Sonora (2002) find slower speeds of adjustment for city real exchange rates using a pooled approach.

17 Engel (1999) also constructs real exchange rates from sectoral price indices and from wholesale price data. We do not consider this portion of his evidence since we do not have comparable data for US regions.
} 
The most comprehensive study of expenditure shares internationally is by Kravis, Summars and Heston (1982). They find that tradables/nontradable in 1975 account for 0.55 of expenditures for Japan, 0.50 for France and 0.50 for Germany. Furthermore, Engel's expenditure shares are also low when compared to shares derived from production data. ${ }^{18}$ De Gregorio, Giovannini and Wolf (1994) define tradables as manufacturing and agriculture. If we use this definition, the share of nontradables between 1960 and 1972 is 0.70 for Canada, 0.62 for France, 0.54 for Germany, 0.56 for Japan and 0.66 for the US. ${ }^{19}$

The recent theoretical literature on international macroeconomics provides a final reason to consider higher shares. This work is based on the proposition that commodity markets are poorly integrated internationally see Obstfeld and Rogoff (2001). If we accept this premise, it suggests nontradables must account for a large portion of expenditure..$^{20}$

To see if expenditure shares explain some of the difference between the regional and international results, we conduct two exercises with Engel's fixed exchange rate data. The first uses his expenditure shares while the second sets the share of nontradables equal

\footnotetext{
18 There are two reasons to prefer nontradables shares derived from production data to shares derived from expenditure data. In the first place it is easier to apportion sectors to tradables/nontradables than to determine which items of expenditure are tradable. Second, the commodities equals tradables approach understates the relative importance of nontradables since many services are inputs into the production of commodities.

19 These estimates are from World Bank's World Tables, Volume Three. Our estimates probably understate the nontradables share for these years since many sectors within manufacturing and agriculture were nontraded during the 1960's.

20 Obstfeld and Rogoff (2001) argue that if a large part of manufacturing is nontradable due to transport costs and other impediments to trade then the nontradables share may be closer to 0.75 or 0.8 than to the traditional estimates of 0.6 .
} 
to 0.6 for all countries. ${ }^{21}$ Our expenditure share of 0.6 is intended as a plausible upper bound. For that reason, we do not see the results as conclusive. Rather they illustrate the importance of expenditure shares.

Figure 4 gives the MSE decompositions for Canada, France, Germany, Italy and Japan. Following Engel (1999), we use the B1 measure. The decompositions use monthly data from January 1962 to December 1972..22 We also provide ninety five percent confidence intervals for our estimates.

Figure 4

\section{MSE Decompositions for Fixed Exchange Rates}

a. Canada

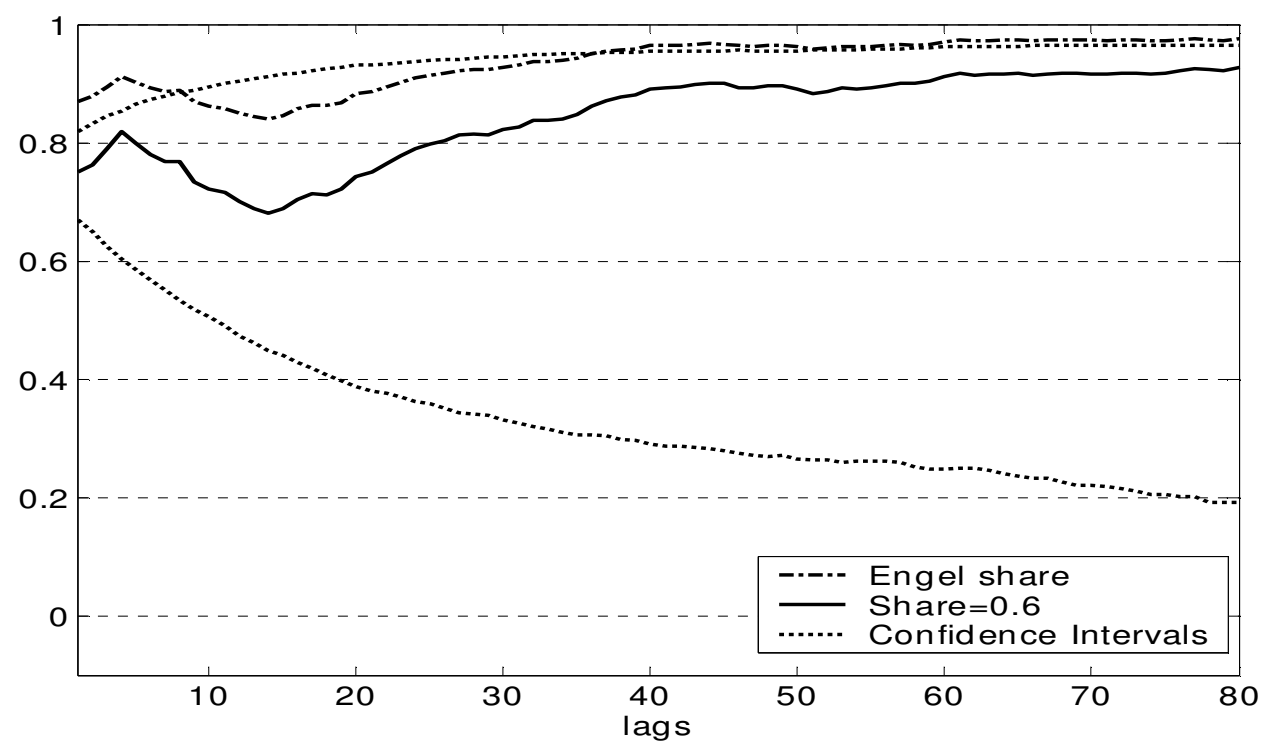

21 We obtained the data at http://www.ssc.wisc.edu/ cengel/data.htm.

22 Engel (1999) uses data from 1962 to 1969. Our results also hold for the shorter period. 


\section{b. France}

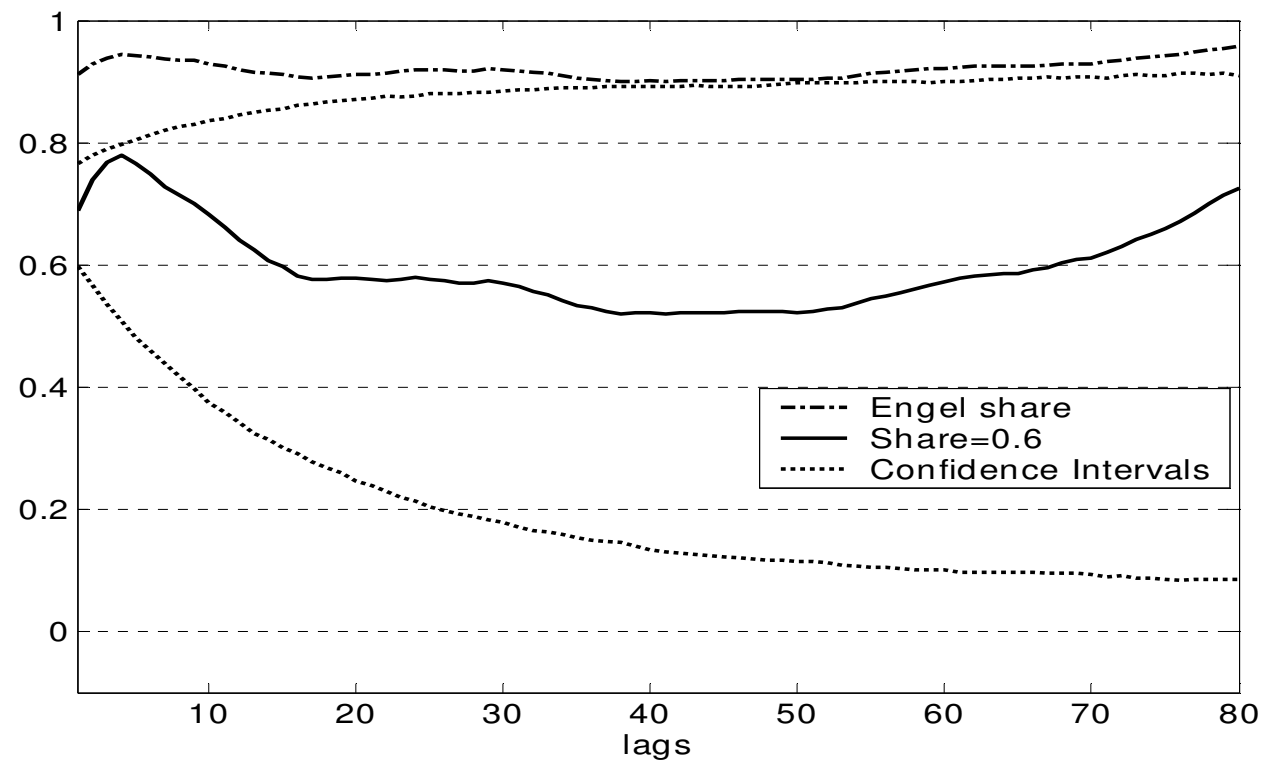

c. Germany

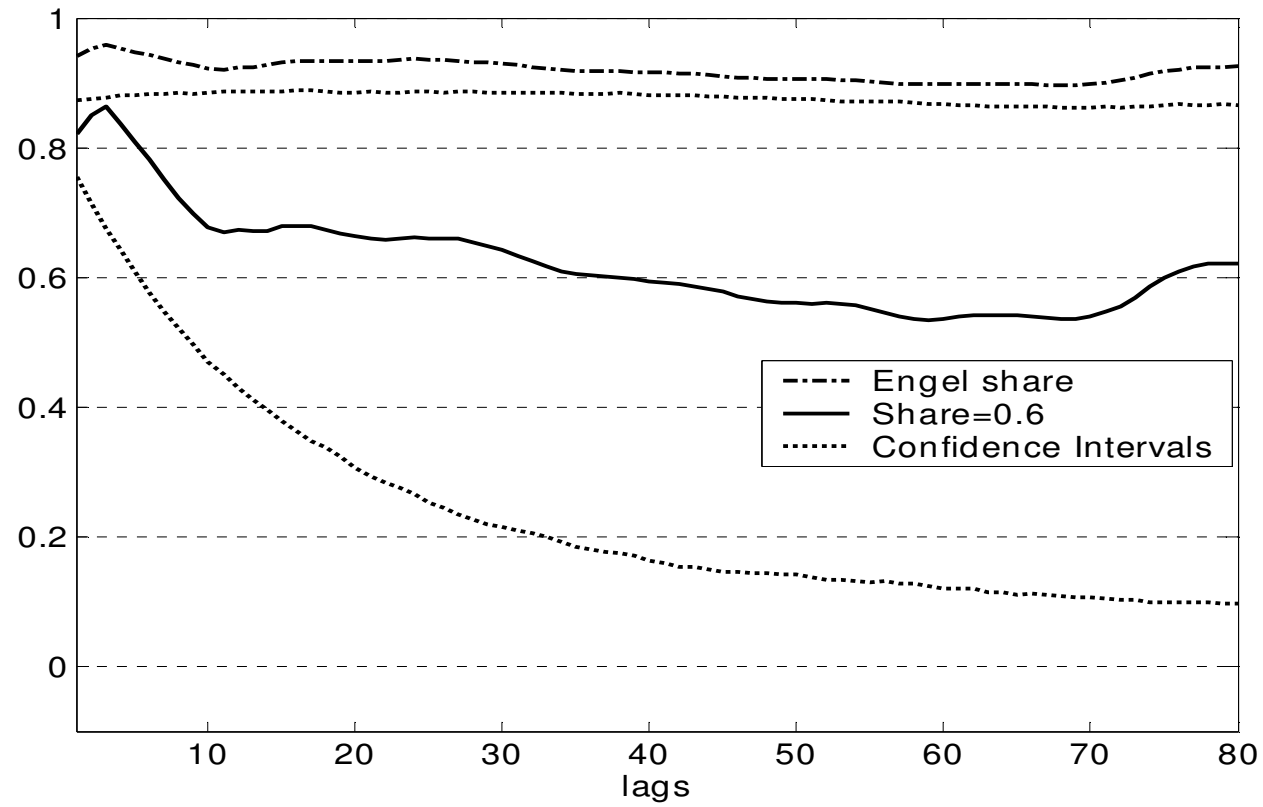


d. Italy

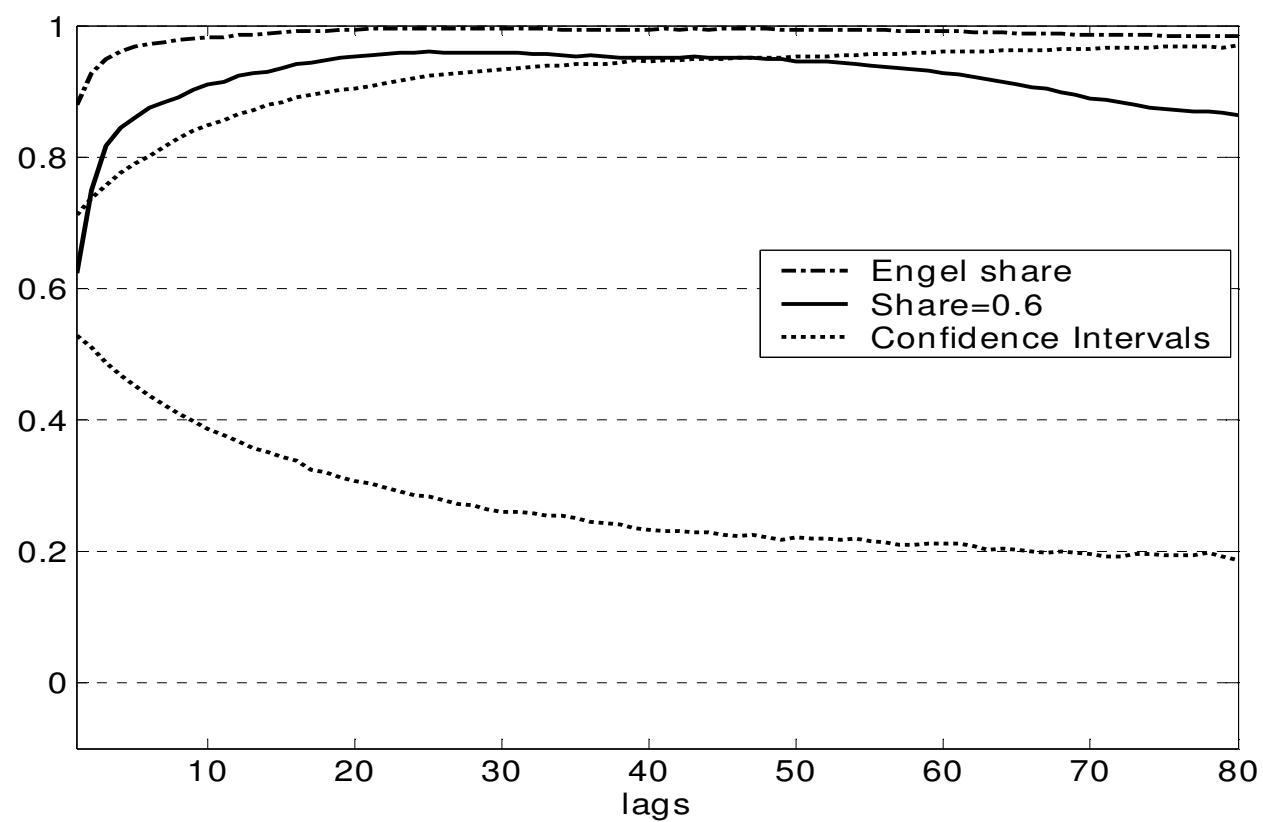

e. Japan

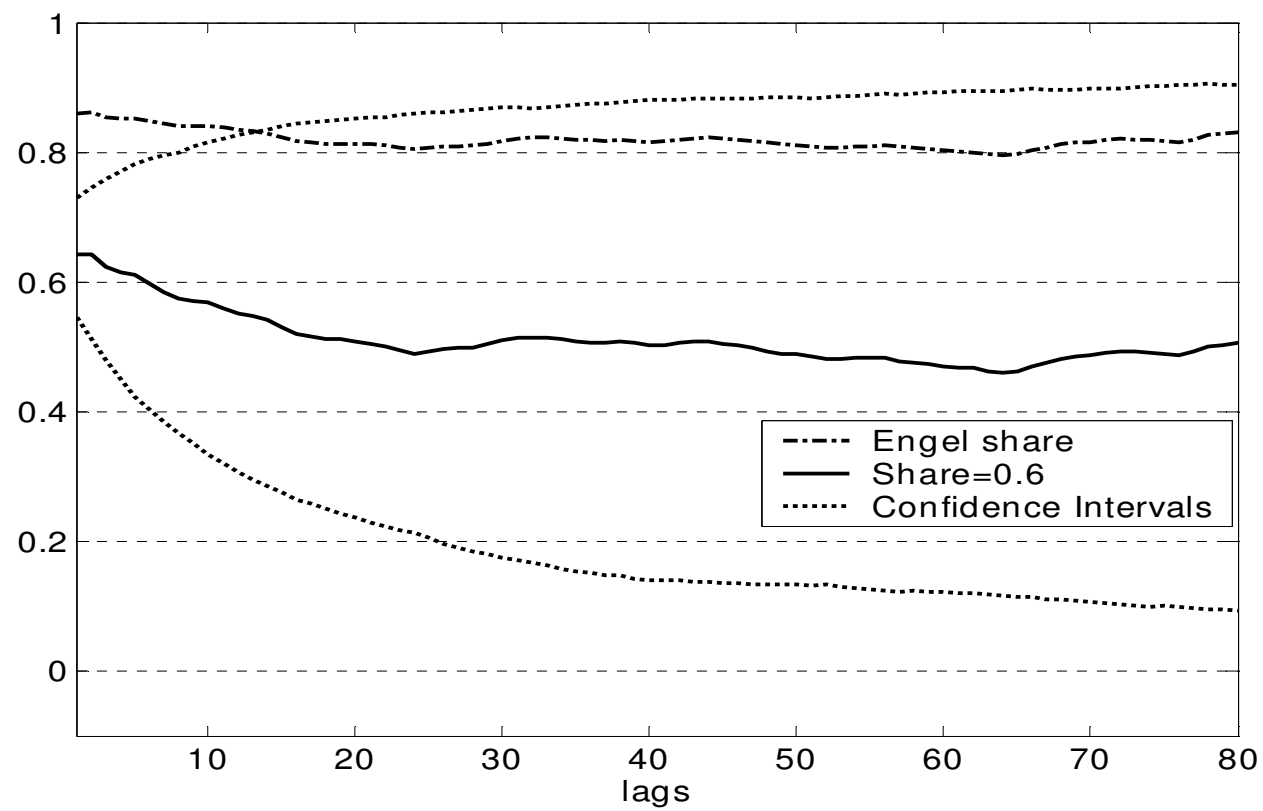


With Engel's shares, we replicate his results- nontradables explain a tiny portion of observed real exchange rate movements for the fixed period. But once we allow for higher shares, nontradables become an important source of real exchange rate movements for three of the five countries.

Consider Germany and France. For horizons of one year or less, tradables account for eighty percent of real exchange rate changes. Thereafter their importance falls to sixty percent. For Japan, tradables account for sixty-five percent of real exchange rate changes at short horizons. The ratio falls to fifty percent at longer horizons. The Japanese case is interesting because of the attention it receives in the literature. Japan experienced rapid growth with real exchange appreciation between 1962 and 1972. During this period Japan appreciated by fifty-five percent relative to the US. It was long assumed that the relative price of nontradables was the driving force behind the real appreciation. ${ }^{23}$ Our results are consistent with this interpretation. For Canada or Italy, however, the expenditure shares make little difference. For both countries traded goods account for eighty-five to ninety-five percent of observed real exchange movements at all horizons.

Are the findings that nontradables matter significant statistically? The evidence is weaker. Following the approach of Engel (1999) we construct ninety five percent confidence intervals using a Monte Carlo experiments. ${ }^{24}$ The intervals are calculated

\footnotetext{
23 These explanations assume that more rapid growth in Japan led to real appreciation by increasing the relative price of nontraded goods. Ceglowski (1996) discusses the literature on Japan.

$24 \mathrm{We}$ construct the confidence intervals as follows. First, given the sample mean and variance of $x_{t+1}{ }^{-} x_{t}$ and $y_{t+1^{-}} y_{t}$, we generate 5,000 artificial series of $x_{t+1^{-}} x_{t}$ and $y_{t+1^{-}} y_{t}$ with the same length as the data by randomly drawing from the normal distribution with mean and variance equal to those of the data. Second
} 
under the null that $x_{t+n^{-}} x_{t}$ and $y_{t+n^{-}} y_{t}$ are independent. If the ratio is within the intervals then this implies that one cannot reject the null that $x_{t}$ and $y_{t}$ are independent random walks. The results with the higher expenditure shares are within the confidence intervals. We also constructed confidence bands for the regional data. In contrast to Figure 4, the ratios are outside the intervals after a few months for US regions.

So far, we have measured the relative importance of tradables by looking at the ratio of the mean squared error of tradables to mean squared error of the real exchange rate. What about the behavior of individual series for $\mathrm{x}$ and $\mathrm{y}$ ? In particular do they behave differently between regional and international data? To understand this, Table 1 provides the MSE for the $\mathrm{x}$ and y variables for US regions from 1978 to 2001 . We also provide the MSE for Canada, France, Germany, Italy and Japan relative to the US for 1962 through 1972.

As we might expect, the MSE for the $\mathrm{x}$ and $\mathrm{y}$ variables are much lower for US regions than countries. Only the MSE of y for Canada is comparable to that for the regions. ${ }^{25}$ The rest of the countries show a much higher variability in $\mathrm{x}$ and $\mathrm{y}$ series as we move to longer horizons.

starting with the first observation of the sample, $x_{1}$ and $y_{1}$, we cumulate the series to get artificial series of $x_{t}$ and $y_{t}$. Finally, we calculate the MSE decompositions of 5,000 cases and choose $126^{\text {th }}$ largest and smallest ratios for each lag horizon. These are the upper and lower bands respectively.

25 With Engel's expenditure shares, the MSE of y is greatly reduced relative to Table 1 for the international data. 


\section{Table1}

\section{Mean Square Errors*}

\begin{tabular}{|c|c|c|c|c|c|c|c|}
\hline & \multicolumn{6}{|c|}{ Lags (n) } & \multirow[b]{2}{*}{80} \\
\hline & 2 & 12 & 22 & 32 & 42 & 62 & \\
\hline \multicolumn{8}{|l|}{ US Regional Data } \\
\hline \multicolumn{8}{|l|}{ West } \\
\hline $\operatorname{MSE}\left(\mathrm{x}_{\mathrm{t}}-\mathrm{x}_{\mathrm{t}-\mathrm{n}}\right)$ & 0.305 & 0.766 & 0.834 & 0.749 & 0.973 & 1.007 & 1.149 \\
\hline $\operatorname{MSE}\left(\mathrm{y}_{\mathrm{t}}-\mathrm{y}_{\mathrm{t}-\mathrm{n}}\right)$ & 0.199 & 1.033 & 2.334 & 3.429 & 3.823 & 4.186 & 7.038 \\
\hline \multicolumn{8}{|l|}{ Midwest } \\
\hline $\operatorname{MSE}\left(\mathrm{x}_{\mathrm{t}}-\mathrm{x}_{\mathrm{t}-\mathrm{n}}\right)$ & 0.304 & 0.559 & 0.781 & 0.890 & 0.991 & 1.055 & 1.367 \\
\hline $\operatorname{MSE}\left(\mathrm{y}_{\mathrm{t}}-\mathrm{y}_{\mathrm{t}-\mathrm{n}}\right)$ & 0.140 & 0.583 & 1.442 & 2.437 & 3.793 & 6.991 & 10.913 \\
\hline \multicolumn{8}{|l|}{ South } \\
\hline $\operatorname{MSE}\left(\mathrm{x}_{\mathrm{t}}-\mathrm{x}_{\mathrm{t}-\mathrm{n}}\right)$ & 0.136 & 0.333 & 0.490 & 0.596 & 0.807 & 0.999 & 1.123 \\
\hline $\operatorname{MSE}\left(\mathrm{y}_{\mathrm{t}}-\mathrm{y}_{\mathrm{t}-\mathrm{n}}\right)$ & 0.097 & 0.580 & 1.541 & 2.618 & 4.080 & 7.531 & 12.182 \\
\hline \multicolumn{8}{|l|}{ International Data } \\
\hline \multicolumn{8}{|l|}{ Share $=0.6$} \\
\hline \multicolumn{8}{|l|}{ Canada } \\
\hline $\operatorname{MSE}\left(\mathrm{x}_{\mathrm{t}}-\mathrm{x}_{\mathrm{t}-\mathrm{n}}\right)$ & 0.641 & 1.348 & 3.560 & 6.719 & 13.403 & 35.830 & 67.828 \\
\hline $\operatorname{MSE}\left(\mathrm{y}_{\mathrm{t}}-\mathrm{y}_{\mathrm{t}-\mathrm{n}}\right)$ & 0.200 & 0.579 & 1.103 & 1.305 & 1.583 & 3.416 & 5.324 \\
\hline \multicolumn{8}{|l|}{ France } \\
\hline $\operatorname{MSE}\left(\mathrm{x}_{\mathrm{t}}-\mathrm{x}_{\mathrm{t}-\mathrm{n}}\right)$ & 2.934 & 11.475 & 22.239 & 39.580 & 58.615 & 157.887 & 528.325 \\
\hline $\operatorname{MSE}\left(\mathrm{y}_{\mathrm{t}}-\mathrm{y}_{\mathrm{t}-\mathrm{n}}\right)$ & 1.039 & 6.444 & 16.486 & 31.417 & 53.674 & 113.334 & 200.417 \\
\hline \multicolumn{8}{|l|}{ Germany } \\
\hline $\operatorname{MSE}\left(\mathrm{x}_{\mathrm{t}}-\mathrm{x}_{\mathrm{t}-\mathrm{n}}\right)$ & 1.600 & 5.645 & 14.842 & 26.627 & 38.794 & 66.298 & 160.547 \\
\hline $\operatorname{MSE}\left(\mathrm{y}_{\mathrm{t}}-\mathrm{y}_{\mathrm{t}-\mathrm{n}}\right)$ & 0.284 & 2.735 & 7.697 & 16.026 & 27.092 & 56.358 & 98.086 \\
\hline \multicolumn{8}{|l|}{ Italy } \\
\hline $\operatorname{MSE}\left(\mathrm{x}_{\mathrm{t}}-\mathrm{x}_{\mathrm{t}-\mathrm{n}}\right)$ & 0.916 & 14.606 & 39.882 & 75.424 & 114.206 & 156.272 & 139.182 \\
\hline $\operatorname{MSE}\left(\mathrm{y}_{\mathrm{t}}-\mathrm{y}_{\mathrm{t}-\mathrm{n}}\right)$ & 0.309 & 1.208 & 1.824 & 3.404 & 5.854 & 13.299 & 22.231 \\
\hline \multicolumn{8}{|l|}{ Japan } \\
\hline $\operatorname{MSE}\left(\mathrm{x}_{\mathrm{t}}-\mathrm{x}_{\mathrm{t}-\mathrm{n}}\right)$ & 2.129 & 8.878 & 20.915 & 42.277 & 66.870 & 117.139 & 204.961 \\
\hline $\operatorname{MSE}\left(\mathrm{y}_{\mathrm{t}}-\mathrm{y}_{\mathrm{t}-\mathrm{n}}\right)$ & 1.189 & 7.259 & 20.923 & 39.858 & 65.403 & 133.936 & 200.646 \\
\hline
\end{tabular}

*All quantities are multiplied by $10^{4}$. 


\section{Summing Up}

This paper examines real exchange rate behavior for fixed exchange rate regimes. We find strong evidence that purchasing power parity holds for traded good across US regions. As a result, nontradables play the central role in regional real exchange rate movements. They account for eighty percent of real exchange rate changes for US regions at medium and longer time horizons. In addition, we find evidence to suggest that the relative price of nontradables explains a significant portion of real exchange rate changes internationally if we allow for higher expenditure shares.

\section{References}

Cecchetti, S, Mark N. and R. Sonora. "Price Level Convergence Among United States Cities: Lessons for European Central Banks." International Economic Review 4 (2002), 1081-1099.

Ceglowski, J. "The Real Yen Exchange Rate and Japanese Productivity Growth." Review of International Economics 4 (1996), 54-63.

Chen. L. and J. Devereux. "What can City Price Data tell us about Purchasing Power Parity?" Journal of International Money and Finance 22 (2003), 213-222.

Culver, S. and D. Papell. "Panel Evidence of Purchasing Power Parity Using Intranational and International Data." Mimeo. University of Houston, 1999.

De Gregorio, J, Giovannini, A and H. Wolf. "International Evidence on Tradables and Nontradables Inflation." European Economic Review 38 (1994), 1225-44.

Engel, C. "Accounting for U.S. Real Exchange Rate Changes." Journal of_Political Economy 107 (1999), 507-538.

Engel, C. and J. Rogers. "How Wide is the Border?" American Economic Review 86 (1996), 1112-1125.

Engel, C. and J. Rogers. "Violating the Law of One Price: Should we Make a Federal Case out of it." Journal of Money Credit and Banking 33 (2001), 1-15.

Helliwell, J. How Much Do Borders Matter. Brookings Institution, 1998. 
Hess, G and E van Wincoop. (eds) Intranational Macroeconomics. Cambridge University Press, New York, November 2000.

Kravis, I. Summars, R. and A. Heston. World Product and Income. John Hopkins University Press, 1982.

Mendoza, Enrique. "On the Instability of Variance Decompositions of the Real Exchange Rate across Exchange-Rate-Regimes: Evidence from Mexico and the United States." NBER Working Paper Series, No 7768, 2000.

Murray, C. and D. Papell. "The Purchasing Power Parity Persistence Paradigm." Journal of International Economics 56 (2002), 1-19.

Obstfeld, M. "International Macroeconomics: Beyond the Mundell-Fleming Model." IMF Staff Papers 147 (2001), 1-39.

Obstfeld, M. and K. Rogoff. Foundations of International Macroeconomic. Cambridge: MIT Press (1996).

Obstfeld, M. and K. Rogoff. "The Six Major Puzzles in International Macroeconomics: Is there a Common Cause?" In NBER Macroeconomics Annual 2000, edited by B.

Bernanke and K. Rogoff. MIT Press, 2000.

Obstfeld, M. and K. Rogoff. "Perspectives on OECD Capital Market Integration: Implications for US Current Account Adjustment." In Federal Reserve Bank of Kansas City Global Economic Integration: Opportunities and Challenges, 2001.

O'Connell, P and S. Wei. "The Bigger they are the Harder they Fall." Journal of International Economics 56 (2002), 21-53.

Parsley, D. and S. Wei. "Convergence to the Law of One Price Without Trade Barriers or Currency Fluctuations.” Quarterly Journal of Economics 108 (1996), 1211-1236.

Parsley, D. and S. Wei. "Explaining the Border Effect: The Role of Exchange Rate Variability, Shipping Costs, and Geography." Journal of International Economics 55 (2001), 87-105.

Rogers, J. H. "Monetary Union, Price Level Convergence and Inflation: How Close is Europe to the United States" International Finance Discussion Paper 740. Federal Reserve Board, Washington DC. (2002)

Salter, W. E. G. "Internal and External Balance: The Role of Price and Expenditure Effects." Economic Record 35 (1959), 226-238. 